Rational Partisan Theory, Uncertainty and Spatial Voting: Evidence for the Bank of England's MPC

Arnab Bhattacharjee and Sean Holly

January 2010

CWPE 1002 


\title{
Rational Partisan Theory, Uncertainty and Spatial Voting: Evidence for the Bank of England's MPC.*
}

\author{
Arnab Bhattacharjee ${ }^{\$}$ and Sean Holly $\# \dagger$
}

July 2009

\begin{abstract}
The transparency and openness of the monetary policymaking process at the Bank of England has provided very detailed information on both the decisions of individual members of the Monetary Policy Committee and the information on which they are based. In this paper we consider this decision making process in the context of a model in which inflation forecast targeting is used but there is heterogeneity among the members of the committee. We find that rational partisan theory can explain spatial voting behaviour under forecast uncertainty about the output gap. Internally generated forecasts of output and market generated expectations of medium term inflation provide the best description of discrete changes in interest rates, in combination with uncertainty in the macroeconomic environment. There is also a role for developments in asset housing and labour markets. Further, spatial voting patterns clearly differentiates between internal and externally appointed members of the Monetary Policy Committee. The results have important implications for committee design and the conduct of monetary policy.
\end{abstract}

JEL Classification: E42, E43, E50, E58.

Keywords: Monetary policy, interest rates, Monetary Policy Committee, Committee decision making.

${ }^{*}$ Correspondence: A. Bhattacharjee, School of Economics and Finance, University of St. Andrews, Castlecliffe, The Scores, St. Andrews KY16 9AL, UK; Tel.: +44 (0)1334 462423; Fax: +44 (0)1334 462444; email: ab102@st-andrews.ac.uk.

†\$ University of St. Andrews, UK; \# University of Cambridge, UK. 


\section{Introduction ${ }^{1}$}

There is a substantial literature in the US that uses information from transcripts of the proceedings of the FOMC to study the monetary policymaking process. See for example Belden (1989), Havrilesky and Gildea (1992), McGregor (1996), Chappell and McGregor (2004) and Chappell et al. (2005). This body of work has provided a number of insights into how committees work and the role played by individual members (especially the Chairman), and has been followed much more recently by studies of the monetary policymaking process of the Bank of England. In 1992, the United Kingdom, following New Zealand and Sweden, adopted inflation targeting. This was augmented by a much more open system of decision-making, but ultimately decisions on interest rates were still made by the Government. In 1997 the Bank of England was given full operational independence. To support this new policy regime, very detailed information about interest rate decisions has been provided. Recent literature has used such detailed information, including votes by individual members, to study several aspects of monetary policymaking at the Bank of England's Monetary Policy Committee (MPC). ${ }^{2}$

The above empirical literature highlights the fact that policymakers tend to differ significantly in the interest rate changes they would prefer. This points to heterogeneity in beliefs across members in a monetary policy committee. Spatial voting theory (Downs, 1957; Black, 1958), where voters evaluate admissible options and cast their vote on the alternative that is closest to their own "ideal point", is a potentially useful framework to identify and study such heterogeneity. At the same time, two important political business cycle theories have developed that can explain observed persistent differences in voting behaviour. While rational partisan theory (Chappell and Keech, 1986; Alesina, 1987, 1988) posits that committee members are ideologically motivated but consistent with their policy preference over time, opportunistic business cycle theory (Nordhaus, 1975; Persson and Tabellini, 1990) suggests

\footnotetext{
${ }^{1}$ We are grateful to Stephanie Daniel for research assistance. The paper has benefited from comments by Jagjit Chadha, David Cobham, Andrew Hughes Hallett, Marcus Miller and Charles Nolan, as well as participants at the MMF Conference, the ECB and European University Institute. The detailed review and constructive comments made by two anonymous referees and a Co-Editor helped improve the paper substantially. Their contribution is gratefully acknowledged. The usual disclaimer applies.

${ }^{2}$ See, for example, Chadha and Nolan (2001), Cobham (2002a, b, 2003), GerlachKristen (2004), Bhattacharjee and Holly (2008) and Hix et al. (2007).
} 
that members ideologically close to the incumbent party may attempt to use their policies to stimulate output before elections. While evidence on both these theories has in general been mixed $^{3}$, there is some evidence that monetary policy making in the Bank of England may be explained partly by political business cycles (Hix et al., 2007).

In this paper we consider the monetary policy decision making process in the context of a model in which inflation forecast targeting is used but there is heterogeneity among the members of the Committee. This heterogeneity does not arise so much from differences in preferences about inflation and output, as from differences in information assimilation. ${ }^{4}$ Specifically, we argue that forecast uncertainty may produce partisan effects on private estimates of the output gap. Under rational voting by inflation targeting members, this in turn translates into differences in voting behaviour within the MPC. However, while most spatial voting applications to monetary policy assume a one-dimensional representation, we find evidence of a preference space in two dimensions. The traditional dove-hawk view is complemented with the activist-pacifist dimension, where external members are either activists or pacifist-doves and all internal members are pacifist-hawks. These findings have important implications for committee design, voting methods as well as appointment of new members.

Our paper touches on a number of additional issues connected to monetary policy. First, there is a large literature that examines the usefulness of characterising monetary policy in terms of a rule. ${ }^{5}$ Based on the argument in Svensson $(1997 \mathrm{a}, \mathrm{b})$ that, given the long and variable lags inherent in policy, it might make more sense to target a forecast of inflation rather than its current value, we use the Svensson (1997a) inflation forecast targeting model in preference to the Taylor rule (Taylor, 1993). Second, interest rate decisions are made in real time and based on current information, while there is often considerable uncertainty about the current state of the economy; see, among others, Orphanides (1998). In this paper we assume that the filtering which is required of current, imperfect measures of economic activity takes place

\footnotetext{
${ }^{3}$ See, for example, Alesina and Summers (1993), McGregor (1996), Carlsen and Pedersen (1999), Chappell and McGregor (2004) and Berlemann and Markwardt (2007).

${ }^{4}$ The common assumption that preferences concerning output and inflation vary between members (Neumann, 2002; Sibert, 2003) is not consistent with an inflation targeting central bank. Instead, we highlight heterogeneity in information acquisition about a supply shock, which is potentially costly; see also Lagerlöf (2001).

${ }^{5}$ See Svensson (1997a), Woodford (1999) and Orphanides (2003) for further discussion.
} 
as part of the internal procedures of the Bank of England. ${ }^{6}$ Our empirical results indicate that forecasts of inflation and output provides the best explanation of UK monetary policy since 1997, which supports the inflation forecast targeting rule. Third, we find some evidence that developments in asset markets matter, which is in line with the extensive literature on the role of asset markets in monetary policy decisions. ${ }^{7}$

Information on the precise voting record of each member allows investigation of heterogeneity across the MPC, for which we find substantial evidence. This raises the question as to why there is heterogeneity across the Committee in the first place, given that they all share a common pool of information and individual members have many opportunities to make their views known prior to an interest rate decision. In this paper, we assume that all MPC members are inflation targeters, so that preference heterogeneity is absent. Instead we believe that heterogeneity reflects differing views of the world, with some members attaching greater importance to particular developments in the economy than others. Some individual members may attach greater importance to developments on the supply side, which in the presence of forecast uncertainty translates into different views on the size of the output gap. Similarly, some other members may attach greater importance to asset markets, while others may disagree with the majority view because they believe the transmission mechanism of monetary policy is different. ${ }^{8}$

We model the process of information acquisition under heterogeneity as a signal extraction problem, with individual members optimally combining the forecast of the majority with their own views. We find that heterogeneity in the reaction to macroeconomic uncertainty generate spatial voting patterns that clearly differentiate between internal and external MPC members. These results support rational partisan theory and have important implications for the institutional setting and conduct of monetary policy.

The plan of the paper is as follows. In section 2 we present a simple model of inflation forecast targeting and discuss possible sources of heterogeneity and then turn to the contribution rational partisan theory can play in explaining this heterogeneity. In section 3 we discuss the estimation problem.

\footnotetext{
${ }^{6}$ See Budd (1998) for a description.

${ }^{7}$ See, for example, Cecchetti et al. (2000) and Bernanke and Gertler (2001).

${ }^{8}$ See, for example, Belden's (1989) analysis of dissents in FOMC votes and Chadha and Nolan's (2001) analysis in the UK context. Other measures of uncertainty discussed in the literature include forecast revisions (Chadha and Nolan, 2001) and dispersion in survey correspondents' views on inflation (Bomberger, 1996).
} 
In section 4 we report and discuss our empirical results. Finally, we present conclusions in section 5 .

\section{The Model}

We adopt a highly stylised model of the monetary policymaking process and abstract from many issues that have been the focus of much of the recent literature. We do this deliberately in order to have a model that appears to align best with how central banks view the monetary transmission process and to provide a justification for the way in which policy appears to be conducted. ${ }^{9}$ This allows us to show that when there are delays in the monetary transmission process so that changes in interest rates take time to effect output and in turn for output to affect inflation, the monetary authority uses a so-called 'inflation forecasting' rule. This in turn has implications for the way in which interest rates are set. Within the context of this simple stylised model, we introduce a role for heterogeneity amongst members of the Monetary Policy Committee.

\subsection{The inflation process}

Our model for the inflation process is structured as follows:

$$
\begin{aligned}
\pi_{t} & =\pi_{t-1}+\alpha y_{t-1}+\epsilon_{t} \\
y_{t} & =\beta_{1} y_{t-1}-\beta_{2}\left(r_{t-1}-\pi_{t-1}\right)+\eta_{t}
\end{aligned}
$$

$\pi_{t}$ is the inflation rate in period $t, y_{t}$ is the output gap (the difference between the log of output and the log of potential output), and $r_{t}$ the nominal interest rate. $\eta_{t}$, a supply shock and $\varepsilon_{t}$, a demand shock, are iid shocks in period $t$ not observable in period $t-1$. The coefficients $\alpha$ and $\beta_{2}$ are positive; $\beta_{1}\left(0<\beta_{1}<1\right)$ measures the degree of persistence in the output gap. The output gap depends negatively on the real lagged interest rate. The change in inflation depends on the lagged output gap. The output gap is normalised to zero in the long run.

These pure delays in the impact of the output gap on inflation and of interest rates on the output gap captures in the most straightforward way

\footnotetext{
${ }^{9}$ In particular, for expositional purposes we ignore forward-looking expectations and issues arising consequently from time inconsistency.
} 
the central bankers' stylised model of the monetary transmission process. The modern generation of New Keynesian models with nominal inertia and imperfect competition still exhibit jumps in output and inflation in response to shocks which will blur the pure delays embodied in equations (1) and (2). The intertemporal loss function is:

$$
L_{t}=\frac{1}{2} E_{t} \sum_{\tau=t}^{\infty}\left[\delta^{\tau-t}\left[\left(\pi_{\tau}-\pi^{*}\right)^{2}\right]+\lambda y_{\tau}^{2}\right] .
$$

Here, $E_{t}$ denotes expectations conditional on information available in period t. $\pi^{*}$ is the inflation target, and $\delta$ is the discount rate $(0<\delta<1)$. The policymaker minimises the present discounted value of squared deviations of inflation from its target and the output gap. $\lambda$ is the weight the policymaker attaches to the output gap, with the weight on inflation normalised to unity.

For the special case of $\lambda=0$, so the policymaker only targets inflation, the central bank can (in expectation) use the current interest rate to hit the target for inflation two periods hence. So the intertemporal problem can be written as a sequence of single period problems. In this case (Svensson, 1997a):

$$
L_{t}=\frac{1}{2}\left[\pi_{t+2 \mid t}-\pi^{*}\right]^{2},
$$

where $\pi_{t+2 \mid t}$ is the forecast of inflation at time period $t+2$ based on information available in period $t$. The central bank minimises the squared deviation of the current two-year inflation forecast, $\pi_{t+2 \mid t}$, from the target. The forecast of $\pi_{t+2}$ at $t$ is

$$
\pi_{t+2 \mid t}=\pi_{t+1 \mid t}+\alpha y_{t+1 \mid t}
$$

and

$$
y_{t+1 \mid t}=\beta_{1} y_{t \mid t}-\beta_{2}\left(r_{t}-\pi_{t \mid t}\right)
$$

where the subscript $t \mid t$ indicates that current realisations of the output gap and inflation may well be imperfectly observed, and need to be forecasted. So:

$$
\pi_{t+2 \mid t}=\alpha\left[\beta_{1} y_{t \mid t}-\beta_{2}\left(r_{t}-\pi_{t \mid t}\right)\right]+\pi_{t+1 \mid t}
$$


Then the rule for setting the interest rate by the monetary authority is:

$$
r_{t}=\pi_{t \mid t}+\frac{1}{\alpha \beta_{2}}\left(\pi_{t+1 \mid t}-\pi^{*}\right)+\frac{\beta_{1}}{\beta_{2}} y_{t \mid t} .
$$

Although an explicit weight is not attached to output losses, current (forecasted) output appears in the rule because the current output gap is informative about future inflation. Recall that this rule is designed to ensure that inflation in period $t+2$ is on the target, $\pi^{*}$. Suppose, initially in period $t$, the actual inflation rate and the inflation rate in the next period were equal to the target and the output gap, $y_{t}$, is zero. In this case $r_{t}=\pi_{t \mid t}$. Let there then be a demand shock, $\eta_{t+1}>0$ in period $t+1$ that raises $y_{t+1}$ and drives inflation in period $t+2$ above target. In order, in the face of the positive demand shock to ensure that inflation in period $t+3$ is back on target, the monetary authority leans against the rise in $y_{t+1}$ and against the expected rise in inflation in $t+2$.

There are three key features of this relationship that bear upon the empirical work we report later.

First, decisions about interest rates in period $t$ depend upon expectations of what inflation will be in the future. This is the inflation forecasting rule proposed by Svensson. It can be contrasted for example with the standard Taylor rule in which the interest rate responds to current or lagged realisations of inflation and output.

Secondly, In Svensson's original formulation $\pi_{t \mid t}$ and $y_{t \mid t}$ are known. In practice, as Orphanides (1998) has pointed out, current inflation and the current output gap are not observed in real time. For expositional purposes we are assuming that the decision period coincides with the observation period. In practice data are available at different frequencies from daily to yearly. ${ }^{10}$

And, thirdly, the form of the rule has important implications for the conduct of monetary policy. In the simple model above the policymaker can only affect inflation two periods into the future. At each point in time when a decision is being made, the policymaker sets the interest rate to achieve (in expectation) the target in two period's time. ${ }^{11}$ To quote a former member of the MPC.

\footnotetext{
${ }^{10}$ It is straight forward to cast this problem of optimally combining data of different frequencies as a filtering problem. See for example, Corrado and Green (1988).

${ }^{11}$ It is being assumed here that the policy horizon corresponds to two years (or so) into the future (see King 2002).
} 
"When I was a member of the MPC I thought that I was trying, at each forecast round, to set the level of interest rates so that, without the need for future rate changes, prospective (forecast) inflation would on average equal the target at the policy horizon. This was, I thought, what the exercise was supposed to be." (Goodhart, 2001).

In practice the MPC meets monthly, and sets the interest rate in order to achieve the target inflation rate at the policy horizon. However, a decision to change the interest rate in period $t$ (relative to the decision that was made in period $t-1$ ) can only be the result of new information becoming available in period $t .{ }^{12}$ For example, new information suggesting a build up in pressures in labour markets may call for a rise in interest rates in order to keep inflation on target in two period's time.

\subsection{Heterogeneity and Rational Partisan Theory}

The above can be thought of as a highly stylised model for how the central bank sees the world. We focus on a strict inflation targeting regime, so preference heterogeneity (that is, variation in $\lambda$ ) is not meaningful. It is also possible that individual members look to a wider information set than that provided by projections or forecasts of only output and inflation. It is known that as part of the deliberations of the MPC prior to the announcement of a decision on interest rates, a wide range of economic indicators are looked at. Our empirical analysis, therefore, includes developments in housing markets, exchange rates, equity and the labour market.

As emphasized in Hibbs (1994), a useful way to represent uncertainty, and consequent heterogeneity within the MPC, is to assume partisan policymakers represent different views about the economy. In this paper, we take the second view germane in the "rational partisan theory" (Chappell and Keech, 1986; Alesina, 1987, 1988), and attribute heterogeneity to rational partisan decision-making within the MPC.

However, our model is somewhat different from other applications of partisan political cycles to monetary policy. Specifically, our main focus here

\footnotetext{
${ }^{12}$ This is not a general result. In a model with a more complicated transmission mechanism, in response to a shock to the inflation rate which knocked it off the target, the optimal rule might indicate that it would require a series of changes to the interest rate in order to bring inflation back on target.
} 
is on forecast uncertainty, and on how this translates into differing views on the magnitude of the output gap, which in turn leads to variations in votes across members of the MPC. For this purpose, we start with the two-sector rational partisan theory model discussed, among others, in Morton (1996), where voters' responses to unanticipated shocks vary with the sectors that they represent ${ }^{13}$. This is because the shocks cause different variation in output in different sectors, and leads to higher activism for members anticipating higher variation than others. In the context of a Monetary Policy Committee with members representing different sectors of the economy (see Waller, 1992), this framework implies that members form different private estimates of the output gap, which when combined optimally with the central forecast leads to differences in preferred interest rate changes. Further, not only does the degree of forecast uncertainty affect these initial private estimates, they are also related to the degree of activism demonstrated by different members of the MPC.

Based on the above discussion, we adopt an approach in which heterogeneity arises from differing views about the state of the economy, and specifically the level of the output gap. ${ }^{14}$ Each member has the same (public) information set but augments this with private information. This can take different forms. An individual member may dissent from the consensus forecast or an individual member may have particular expertise that leads to more weight being attached to particular kinds of information compared to the average. Since the internal dynamics of committee decision making can result in a measure of sharing of expertise (see Geanakoplos, 1992; Bicchieri, 1993), we shall assume that the decision of each individual member is ultimately based on commonly shared information as well as private views that cannot be shared fully with the other members of the MPC, or to which the other members of the Committee do not attach importance.

To model this process, we draw on a growing game theoretic literature on committee decision making involving issues such as strategic voting, the acquisition of information, possible conflicts of interest, and how informa-

\footnotetext{
${ }^{13}$ It should be stressed here that the individual members of the MPC are not representatives of particular interests or sectors. They retain their independence but nevertheless have views that attach greater importance to some parts of the economy.

${ }^{14}$ In the discussion of differing views of the MPC members in the September 2006 meeting of the MPC (Bank of England, 2006), there is explicit acknowledgement that different members place different weights on the same macroeconomic events and implicitly also that they may hold different views on the magnitude of the output gap.
} 
tion is communicated in committees (see Gerling et al. (2005) for a survey). Following this line of research, we can think of the decision-making process by the MPC as a two-stage process. In this first stage there is deliberation about the state of the economy (Gerlach-Kristen, 2003; Meade and Stasavage, 2004), staff economists present conjunctural analyses of recent events, members share information and views and eventually a central forecast, with agreed error bands in the form of a fan chart, is arrived at. Nevertheless, at the second stage, despite this sharing of knowledge many MPC members will choose an interest setting different to the central estimate.

This process can be cast as a simple signal extraction problem. Suppose there is an estimate of the output gap $y_{t}^{b}$, which is agreed upon after deliberation. This is an unbiased estimate of the true output gap with ${ }^{15}$

$$
y_{t}^{b}=y_{t}+\omega_{t}^{b} \text { with } \omega_{t}^{b} \backsim N\left(0, \sigma_{\omega^{b}}^{2}\right) .
$$

Each committee member in turn formulates her own estimate of the output gap as:

$$
y_{t}^{j}=\beta x_{t}^{j}+\omega_{t}^{j} \text { with } \omega_{t}^{j} \backsim N\left(0, \sigma_{\omega^{j}}^{2}\right), \text { for } j=1, . . m,
$$

where $x^{j}$ denotes a $g \times 1$ vector of possible variables that the $j$-th MPC member may take notice of (including private information contained in asset and labour market developments, for example), and

$$
y_{t}=E\left(\beta x_{t}^{j}\right) \text {. }
$$

The $j$-th variance term $\sigma_{\omega^{j}}^{2}$ captures both objective and subjective confidence in the estimate of $y_{t}$ 's. For the $j$-th member the estimate of $y_{t}$ that minimises the forecast error variance and combines optimally the bank forecast and the private forecast is given by:

$$
y_{t}^{d j}=y_{t}^{b}+\kappa^{j}\left(y_{t}^{j}-y_{t}^{b}\right)
$$

where $y_{t}^{d j}$ is the final estimate by the $j$-th member of the output gap and $\kappa^{j}$ is:

$$
\kappa^{j}=\frac{\sigma_{\omega^{b}}^{2}}{\sigma_{\omega^{b}}^{2}+\sigma_{\omega^{j}}^{2}} .
$$

\footnotetext{
${ }^{15}$ Strictly speaking, the fan charts that the Bank produces allow for possible asymmetry, and hence the errors may not be normally distributed. We assume normality for the sake of simplicity.
} 
Clearly the more confident the committee member is in her own judgement the smaller $\sigma_{\omega^{j}}^{2}$, and the less weight is attached to the collective forecast.

The internal versus external divide within the MPC, our main focus of analysis, has interesting connections with both rational partisan theory (Waller, 2007) and incentives and reputations of individual members (Sibert, 2003). This connection is conveniently and popularly (see, for example, Hix et al., 2007 and Gerlach-Kristen, 2004) expressed in terms of the dove-hawk dimension. Specifically, externally appointed members of the MPC tend to be more dove-ish, in the sense that their decision rules (or votes) appear to offer greater weight to output stabilisation. For example, in Waller's (2007) partisan setting, it is in society's interest to appoint (in a bipartisan manner) disproportionately more doves to the MPC to represent the unionised labour market. This raises preference for output stabilisation, and therefore counterbalances the effect of a conservative central bank; see also Alesina (1987) and Waller (1992).

Following the above literature, we relate the $j$-th member's estimate of the output gap to their position in the preference space. Assume members at time period $t$ are distributed along the dove-hawk dimension, where $h_{j} \in$ $(-\infty, \infty)$ represents the position of an individual member relative to the central estimate. This indexed member has an initial estimate of the output gap

$$
y_{t}^{j}=y_{t}^{b}+h_{j} \sigma_{\omega^{b}}
$$

where $\sigma_{\omega^{b}}$ is the standard deviation of the central estimate that is published. Further, we assume that extreme hawkish or doveish members place less weight on the central forecast:

$$
\sigma_{\omega^{j}}^{2}=c / h_{j}^{2}, c>0 \text {. }
$$

From (7) and (11), the response of the $j$-th member to the current output gap is

$$
\frac{\beta_{1}}{\beta_{2}} y_{t}^{d j}=\frac{\beta_{1}}{\beta_{2}} y_{t}^{b}+\frac{\beta_{1}}{\beta_{2}}\left[\kappa^{j}\left(y_{t}^{j}-y_{t}^{b}\right)\right]=\frac{\beta_{1}}{\beta_{2}} y_{t}^{b}+\frac{\beta_{1}}{\beta_{2}} f\left(h_{j} \sigma_{\omega^{b}}\right),
$$

where $c$ is some positive constant and

$$
f(x)=x \frac{1}{1+\frac{c}{x^{2}}} \uparrow x
$$


therefore $f\left(h_{j} \sigma_{\omega^{b}}\right)$ is increasing in both $\sigma_{\omega^{b}}$ and $h_{j}$.

Further, Sibert (2003) develops a model of opportunistic behaviour in MPCs, where members are either hawks or doves, but their type is private information. Further, some doves may masquerade as hawks to reduce inflationary expectations which they can exploit later. Hix et al. (2007) find that the degree of hawkishness of some members is hard to pin down; and Hansen and McMahon (2008) provide evidence that the voting behaviour of members of the Bank of England's MPC indeed changes over the duration of their tenure, along the lines argued in Sibert (2003). Based on the above theory and evidence, we assume that degree of hawkishness, $h_{j}$, is an unobserved random effect that potentially takes different values, in line with opportunistic doves in Sibert (2003). We interpret the variance of this random effect as the degree of activism of an indivdual member, which determines how much hawkishness can vary. Further, we can therefore hypothesise that internal MPC members may in general be conservative hawks, while external members are either doves or activists (Sibert's opportunist doves).

The decision rule for the $j$-th member can now be written as:

$$
i_{j t}=\pi_{t \mid t}+\frac{1}{\alpha \beta_{2}}\left(\pi_{t+1 \mid t}-\pi^{*}\right)+\frac{\beta_{1}}{\beta_{2}} y_{t}^{b}+\frac{\beta_{1}}{\beta_{2}} f\left(h_{j} \sigma_{\omega^{b}}\right)+\varsigma_{j t} \quad \text { for } j=1, \ldots, m,
$$

where $\varsigma_{j t}$ is a zero mean process. The decision that is actually implemented, $\Delta i_{t}$, is then a multiple of 25 basis points, and is the vote of the median member ${ }^{16}$.

Two forms of heterogeneity arise in our model from possible 'partisan' responses to unanticipated shocks that induce members to differ about the size of the output gap, even in the absence of preference heterogeneity; see also Morton (1996). Some members may believe that the central estimate of the output gap generated by the staff of the Bank of England underestimates improvements on the supply side that widens the output gap and places less pressure on inflation. In these circumstances a member may prefer on average a lower interest rate. In this case the member is regarded as a 'dove'. Equally, there may be members who err on the side of caution and believe that the central estimate of the output gap over-estimates the degree of slack in the economy. These members who prefer higher interest rates on average are

\footnotetext{
${ }^{16}$ Strictly the voting is sequential, where the initial options are to raise, lower or the keep the interest rate unchanged. If a majority votes for no change there is no further voting. If the vote is for a change, either higher or lower, a vote is then needed on the magnitude of the change.
} 
regarded as 'hawks'. This kind of heterogeneity can be thought of as falling along a dove-hawk dimension. The second form of heterogeneity is activism related to changing degrees of hawkishness (Sibert, 2003).

In our empirical analysis, we segregate these two sources of heterogeneity from one another. The first source of heterogeneity is related to uncertainty about forecasts of the output gap, which can be measured from the fan charts of output growth published by the Bank of England. The second source of heterogeneity is related to the level of activism of a particular member, and can be identified from the residuals of a regression model in which the first source of heterogeneity has been controlled for.

\section{Data and Econometric models}

\subsection{The information set and measurement of variables}

In this section we turn to an empirical examination of monetary policy in the UK. The model discussed in the previous section is a highly stylised characterisation of the process of monetary policymaking. Before moving to an empirical examination of actual decision making, we first outline the two main research questions that our empirical analysis will seek to answer.

First, we wish to test the hypothesis that interest rates will respond more to forecasts of inflation and output than to current and lagged states of the economy, using information provided regularly by the Bank of England in the Inflation Report. We collected information on the kinds of data that the MPC looked at for each monthly meeting. Not all of this information is made use of in this paper but the important issue was to ensure that we conditioned only on what information was actually available at the time of each meeting. Second, based on our model of heterogeneity described in the previous section, we intend to characterise the belief or preference space of the MPC members. Specifically, in addition to the dove-hawk scale, we investigate how far the activist-pacifist dimension additionally included in our analysis enhances inferences on partisan voting behaviour. Further, we investigate whether the position of individual members on the preference space provides additional insights into the political economy of monetary policy decision making.

Our dependent variable is the change in base rate agreed by the MPC at each of its meetings, from June 1997 to March 2005; these meetings are 
monthly and held in the first week of each month, except September 2001 when an additional meeting was held following the events on September 11. Our study of heterogeneity among the members of the MPC is based on decisions of the individual members. The source for these data are the minutes of the MPC meetings.

Assessing monetary policy decisions in the presence of uncertainty about forecast levels of inflation and the output gap requires collection of real-time data available to the policymakers when interest rate decisions are made as well as measures of forecast uncertainty. This contrasts with many studies of monetary policy which are based on realised (and subsequently revised) measures of economic activity (see Orphanides, 2003). The extent to which there is uncertainty about the forecast of the Bank of England can be inferred from the fan charts published in the Inflation Report (Britton et al., 1998).

We also collected information on unemployment, as well data on the underlying state of asset markets (housing prices, share prices and exchange rates). We measure unemployment by the year-on-year change in International Labor Organization (ILO) rate of unemployment, lagged 3 months. The ILO rate of unemployment is computed using 3 month rolling average estimates of the number of ILO-unemployed persons and size of labour force (ILO definition), both collected from the Office of National Statistics (ONS) Labour Force Survey. Housing prices are measured by the year-on-year growth rates of the Nationwide housing prices index (seasonally adjusted) for the previous month (Source: Nationwide). Share prices and exchange rates are measured by the year-on-year growth rate of the FTSE 100 share index and the effective exchange rate respectively at the end of the previous month (Source: Bank of England). The other current information included in the model is the current level of inflation; this is measured by the yearon-year growth rate of RPIX headline inflation lagged 2 months (Source: ONS).

Our model also includes expected rates of future inflation and forecasts of current and future output. One difficulty with using the Bank's forecasts of inflation is that they are not sufficiently informative. By definition, the Bank targets inflation over a two year horizon, so it always publishes a forecast in which (in expectation) inflation hits the target in two years time. To do anything else would be internally inconsistent. Instead, as a measure of future inflation, we use the 4 year ahead inflation expectations implicit in bond markets at the time of the MPC meeting, data on which can be inferred from the Bank of England's forward yield curve estimates obtained 

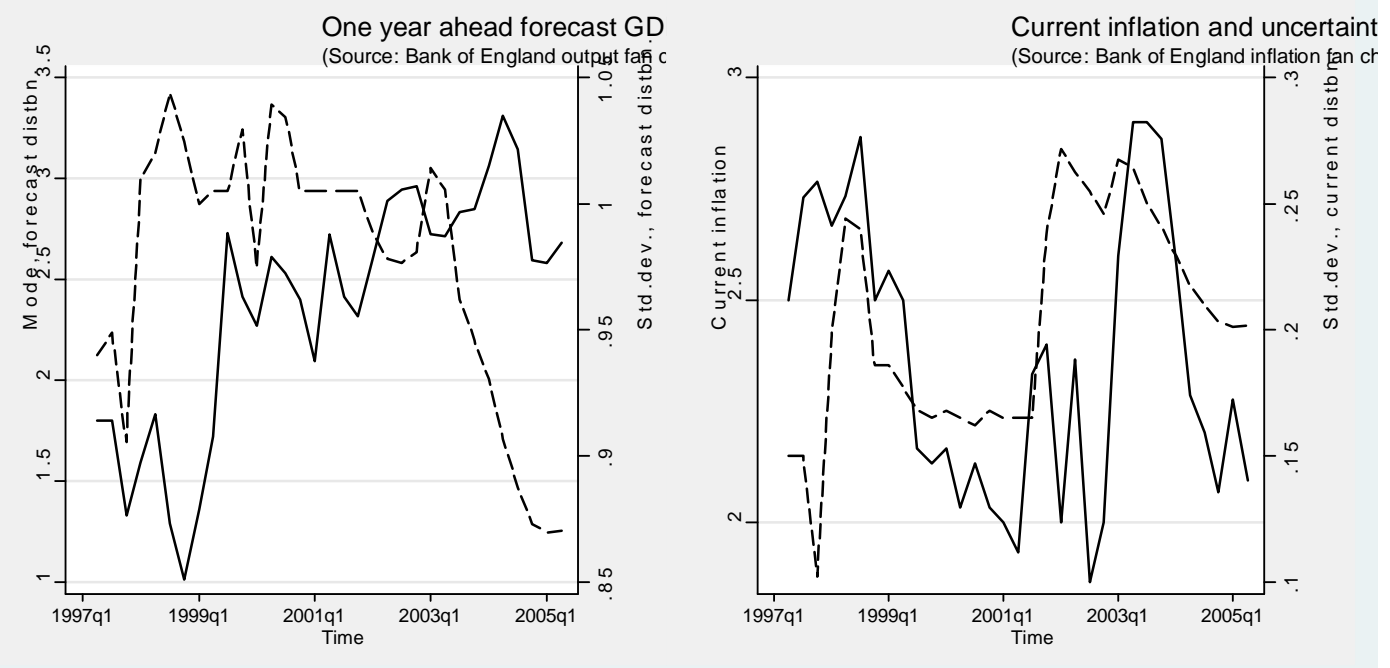

Figure 1: Forecast output growth and inflation, and their uncertainty

from index linked bonds. ${ }^{17}$ For current output, we use annual growth of 2month-lagged monthly GDP published by the National Institute of Economic and Social Research (NIESR) and for one-year-ahead forecast GDP growth, we use the Bank of England's model based mean quarterly forecasts.

As measures of forecast uncertainty, we use the standard deviation of the one-year-ahead forecasts of output growth and inflation. These measures are obtained from the Bank of England's fan charts of output and inflation respectively; details regarding these measures are discussed elsewhere (Britton et al., 1998). The forecasts of output growth and its standard deviation, and likewise for inflation and its standard deviation, show substantial variation over time (Figure 1).

\subsection{An interval censoring model of base rate changes}

Interest rate changes are highly clustered, with a majority of the meetings proposing no change in the base rate (see Figure 2). For the Bank of England

\footnotetext{
${ }^{17}$ We use the four year expected inflation figure because the two year figure is not available for the full sample. In practice the inflation yield curve tends to be very flat after two years.
} 


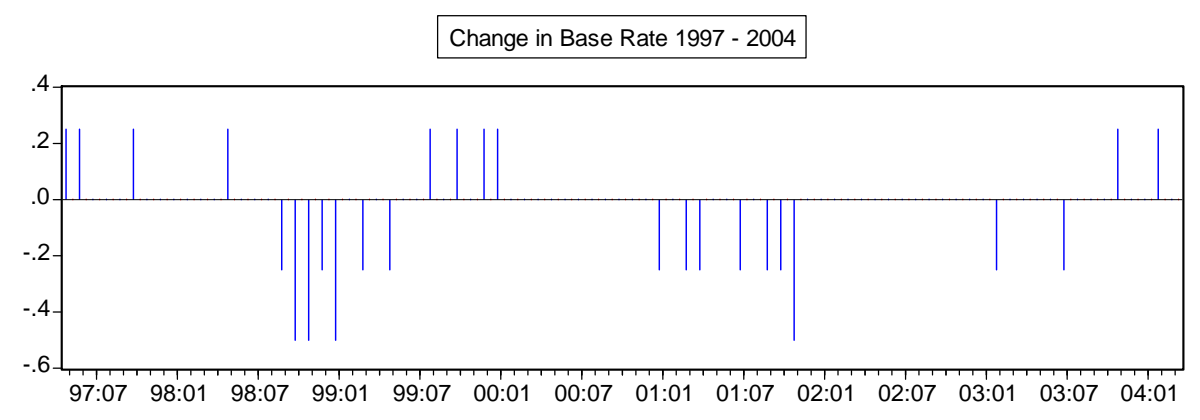

Figure 2: Discrete (Limited Dependent) nature of interest rate changes

MPC over the period of our analysis (June 1997 to March 2005), 69 per cent of the meetings decided to keep the base rate at its current level, 14 per cent recommended a rise of 25 basis points, 13 per cent recommended a reduction of 25 basis points, and 4 per cent a reduction of 0.50 per cent. This clustering has to be taken into account when studying decisions of the MPC. We do not observe changes in interest rates on a continuous or unrestricted scale, we have a limited dependent response variable. Moreover, changes in interest rates are in multiples of 25 basis points. So, in this paper, we use an interval regression framework for analysis; other authors have used other limited dependent variable frameworks, like the logit/ probit or multinomial/ ordered logit/ probit framework. Our choice of model is based on the need to use all the information that is available when monetary policy decisions are made, as well as problems relating to model specification and interpretation of multinomial logit models. We also explored the multinomial and ordered logit models, and found the empirical conclusions to be similar.

The interval regression model (Amemiya, 1973) is a generalisation of the tobit model where the truncation in the dependent variable is possibly different for different observation units, and the truncation cut-offs are known. The observed dependent variable in our case, $\Delta r_{t, o b s}$, is the truncated version 
of the latent monetary policy response variable, $\Delta r_{t}$, which we model as

$$
\begin{aligned}
& \Delta r_{t, o b s}=-0.5 \quad \text { if } \quad \Delta r_{t} \in(-\infty,-0.375) \\
& =-0.25 \text { if } \triangle r_{t} \in[-0.375,-0.20) \\
& =0 \quad \text { if } \quad \Delta r_{t} \in[-0.20,0.20] \\
& =0.25 \text { if } \quad \Delta r_{t} \in(0.20,0.375] \\
& =0.5 \quad \text { if } \quad \Delta r_{t} \in(0.375, \infty)
\end{aligned}
$$

The wider truncation interval when interest rates are unchanged (ie., for $\left.\Delta r_{t, o b s}=0\right)$ may be interpreted as reflecting the conservative stance of monetary policy under uncertainty with a bias in favour of leaving interest rates unchanged.

Under this observation scheme, we estimate the following model of MPC inflation targeting:

$$
\begin{aligned}
\Delta r_{t}= & \alpha_{0}+\alpha_{1} \cdot \Delta r_{t-1}+\alpha_{2} r_{t-1}+\alpha_{3} \pi_{t}+\alpha_{4} \pi_{t+1 \mid t}+\alpha_{5} y_{t \mid t} \\
& +\alpha_{6} y_{t+1 \mid t}+\alpha_{7} \sigma\left(\pi_{t+1 \mid t}\right)+\beta \sigma\left(y_{t+1 \mid t}\right)+\underline{\lambda}^{\prime} \underline{Z}_{t-1}+\varepsilon_{t},
\end{aligned}
$$

where $\underline{Z}_{t-1}$ represents current observations on unemployment $\left(\triangle u_{t}\right)$ and the underlying state of asset markets: housing, equity and the foreign exchange market $\left(P_{h s g, t}, P_{F T S E, t}\right.$ and $P_{e x c h, t}$ respectively). The standard deviation of the one-year ahead forecast of inflation is denoted by $\sigma\left(\pi_{t+1 \mid t}\right)$, and likewise, $\sigma\left(y_{t+1 \mid t}\right)$ denotes standard deviation of forecast output growth. These terms are included to incorporate the notion that the stance of monetary policy may depend on uncertainty relating to current levels of output gap (as well as forecast future output and inflation). We include the term $r_{t-1}$ in the model to encompass a model in which the right hand side could be in terms of the level rather than the difference of the interest rate. Expressing it this way fits more naturally into an interval regression framework where it is the size of the change in the interest rate that determines into which interval it fits. As discussed earlier, heterogeneity in the effect of forecast uncertainty captures partisan responses to uncertainty in the macroeconomic environment. An important objective of our analysis will be to capture and characterise such heterogeneity. 
TABLE 1: Heterogeneity among members:

Voting records of selected MPC members (Jun. 1997 to Mar. 2005)

\begin{tabular}{|l|c|c|c|c|c|c|c|}
\hline \multirow{2}{*}{ Member } & Meetings & \multicolumn{3}{|c|}{ Votes } & \multicolumn{3}{|c|}{ Dissent } \\
\cline { 3 - 8 } & & Lower & No change & Raise & Total & High & Low \\
\hline \hline Allsopp & 37 & 18 & 19 & 0 & 11 & 0 & 11 \\
Barker & 47 & 9 & 32 & 6 & 4 & 1 & 3 \\
Bean & 55 & 10 & 40 & 5 & 1 & 0 & 1 \\
Buiter & 36 & 10 & 10 & 16 & 17 & 9 & 8 \\
George & 74 & 15 & 51 & 8 & 0 & 0 & 0 \\
Goodhart & 36 & 7 & 18 & 11 & 3 & 3 & 0 \\
Julius & 45 & 18 & 25 & 2 & 14 & 0 & 14 \\
King & 95 & 14 & 58 & 23 & 12 & 12 & 0 \\
Nickell & 59 & 15 & 35 & 9 & 10 & 4 & 6 \\
Wadhwani & 37 & 16 & 18 & 3 & 13 & 0 & 13 \\
\hline \hline
\end{tabular}

\subsection{Model of base rate changes with fixed effects het- erogeneity}

Each member of the MPC arrives at her own decision regarding interest rates, and committee interest rate decisions are arrived at by voting on these individual proposals. In addition to the majority decision, the Bank of England also publishes the changes in interest rate proposed by each member of the committee. The voting pattern of individual members of the MPC suggests substantial systematic differences across the committee (Table 1).

For example, of the 37 meetings which Allsopp attended, the votes for 11 were against the consensus decision, and all of these were for a lower interest rate. Similarly, Julius voted against the consensus motion in 14 of the 45 meetings; all of these in favour of a lower interest rate. Wadhwani disagreed 13 out of 37 times, each time in favour of a lower interest rate. On the other hand, King disagreed with the consensus decision in 12 of the 95 meetings he attended, voting for a higher interest rate each time. Buiter dissented in 17 meetings out of 36, voting on 8 occasions for a lower interest rate and 9 times in favour of a higher one. Nickell favoured a different interest rate decision in 10 of the 59 meetings; 6 for a lower interest rate and 4 for a higher interest rate. These data on individual votes offers the opportunity to examine the voting pattern in MPC meetings, and the resulting majority decision; see also King (2002) and Gerlach-Kristen (2004).

In the model of section 2 we have suggested that uncertainty about fore- 
casts will affect monetary policy decisions. Moreover, that there will be heterogeneity in the way individual members incorporate this uncertainty about future levels of output (or different notions about full employment level of future output) into their decisions. This suggests an empirical model of individual MPC members' decisions which allows for potential heterogeneity in the effect, $\beta$, that $\sigma\left(y_{t+1 \mid t}\right)$ has on the interest rate decisions.

However, a simple analysis of the voting records of individual members does not necessarily establish whether a member is a hawk or a dove and an activist or a pacifist. Most external members serve for three years and it is possible that their term of office coincides with a period, when because of the position of the business cycle, interest rates are rising or falling. We need to condition the analysis of heterogeneity on the state of the economy. Under a similar interval regression framework as above, we would then have the model:

$$
\begin{aligned}
\Delta r_{i t}= & \alpha_{0}+\alpha_{1} \cdot \Delta r_{t-1}+\alpha_{2} r_{t-1}+\alpha_{3} \pi_{t}+\alpha_{4} \pi_{t+1 \mid t}+\alpha_{5} y_{t \mid t} \\
& +\alpha_{6} y_{t+1 \mid t}+\alpha_{7} \sigma\left(\pi_{t+1 \mid t}\right)+\beta_{i} \mathbf{I}_{i t} \sigma\left(y_{t+1 \mid t}\right)+\underline{\lambda}^{\prime} \underline{Z}_{t-1}+\varepsilon_{i t},
\end{aligned}
$$

where $\mathbf{I}_{i t}=\mathbf{I}\left[i \in M P C_{t}\right]$ is the indicator that member $i$ was present at the MPC meeting on date $t, \beta_{i}$ represents the fixed effects responsiveness of member $i$ 's decision to uncertainty in the output gap, $\pi_{t+1 \mid t}$ and $y_{t+1 \mid t}$ denote the expected/ forecasted value for inflation and output, and $\sigma\left(\pi_{t+1 \mid t}\right)$ and $\sigma\left(y_{t+1 \mid t}\right)$ denote the uncertainty in future inflation and output respectively. The latent variables $\triangle r_{i t}$ are assigned to intervals in the same way as earlier. However, here there are occasions when individuals MPC members have voted for a reduction of 40 or 75 basis points, or an increase of 50 basis points, hence all votes for change of more than 25 basis points have been assigned to the intervals $\left[\Delta r_{i t, o b s}-0.125, \Delta r_{i t, o b s}+0.125\right)$.

\subsection{Random effects models of base rate changes with heterogeneity among members}

The above fixed effects formulation, however, cannot capture one important aspect of the heterogeneity in the decision processes of MPC members namely, the degree of activism. As noted earlier, some MPC members' decisions are characterized by a greater degree of variability than some others. ${ }^{18}$

\footnotetext{
${ }^{18}$ Buiter and Nickell are prominent examples (Table 1 ). Both have disagreed from the consensus interest rate decisions at a substantial number of meetings, but their proposals
} 
A convenient way of modeling the decision processes of MPC members that captures such features would be through a random effects model; the response of a more activist member would be characterised by a higher variance of the effect of $\sigma\left(y_{t+1 \mid t}\right)$. A standard application of random effects in this context would be the model

$$
\begin{aligned}
\triangle r_{i t}= & \alpha_{0}+\alpha_{1} \cdot \Delta r_{t-1}+\alpha_{2} r_{t-1}+\alpha_{3} \pi_{t}+\alpha_{4} \pi_{t+1 \mid t}+\alpha_{5} y_{t \mid t}+\alpha_{6} y_{t+1 \mid t} \\
& +\alpha_{7} \sigma\left(\pi_{t+1 \mid t}\right)+\underline{\lambda}^{\prime} \underline{Z}_{t-1}+u_{i t},
\end{aligned}
$$

where

$$
u_{i t}=\beta_{i} \mathbf{I}_{i t} \sigma\left(y_{t+1 \mid t}\right)+\varepsilon_{i t},
$$

$\beta_{i} \backsim N\left(\mu_{i}, \sigma_{i}^{2}\right), \varepsilon_{i t} \backsim N\left(0, \sigma^{2}\right)$, and $\varepsilon_{i t}$ and $\beta_{i}$ are independently distributed.

However, this model is not identified. One can only work with this model if $\sigma^{2}=0$, which is not satisfactory.

An alternative random effects model is the following:

$$
\begin{aligned}
\Delta r_{i t}= & \alpha_{0}+\alpha_{1} \cdot \Delta r_{t-1}+\alpha_{2} r_{t-1}+\alpha_{3} \pi_{t}+\alpha_{4} \pi_{t+1 \mid t}+\alpha_{5} y_{t \mid t}+\alpha_{6} y_{t+1 \mid t} \\
& +\alpha_{7} \sigma\left(\pi_{t+1 \mid t}\right)+\underline{\lambda}^{\prime} \underline{Z}_{t-1}+\left(\beta^{*}+\beta_{i}\right) \mathbf{I}_{i t} \sigma\left(y_{t+1 \mid t}\right), \\
& \left(\begin{array}{c}
\beta^{*} \\
\beta_{i}
\end{array}\right) \backsim N\left[\left(\begin{array}{c}
\mu \\
\mu_{i}
\end{array}\right),\left(\begin{array}{cc}
\sigma^{2} & \sigma_{0 i} \\
\sigma_{0 i} & \sigma_{i}^{2}
\end{array}\right)\right], \\
0= & n \mu+\sum_{i=1}^{I} n_{i} \mu_{i}, \\
& \beta_{i} \text { 's are independent of each other, }
\end{aligned}
$$

where $\beta^{*}$ represents the typical response of monetary policy to uncertainty, $\beta_{i}$ is the response of the $i$-th MPC member, ${ }^{19}$ and $n$ and $n_{i}$ 's are the total number of meetings, and the number of meetings that member $i$ attends respectively. Recall the discussion in the previous section regarding the two sources of heterogeneity. This model allows the segregation of the uncertainty term into these two parts, one that is common to all members (depending only on the overall degree of forecast uncertainty), and the other incorporates individual-specific heterogeneity in the degree of activism.

have not been predominantly above or below the consensus decision.

${ }^{19}$ Note that we do not assume independence of $\beta^{*}$ and $\beta_{i}$, but assume that they are jointly normally distributed. 
We estimate this model by assuming that new MPC members go with the general flow for a period of time (the first 3 meetings in our case) before their individual views start getting expressed. ${ }^{20}$ Thus, we can use the votes of all the MPC members in these three initial meetings to estimate $\mu$ and $\sigma^{2}$, and votes in the subsequent meetings to estimate the individual specific heterogeneity parameters. We further assume that $\sigma\left(y_{t+1 \mid t}\right)$ is uncorrelated with the other regressors. ${ }^{21}$ We first estimate the regression

$$
\begin{aligned}
\Delta r_{i t}= & \alpha_{0}+\alpha_{1} \cdot \Delta r_{t-1}+\alpha_{2} r_{t-1}+\alpha_{3} \pi_{t}+\alpha_{4} \pi_{t+1 \mid t}+\alpha_{5} y_{t \mid t}+\alpha_{6} y_{t+1 \mid t} \\
& +\alpha_{7} \sigma\left(\pi_{t+1 \mid t}\right)+\underline{\lambda}^{\prime} \underline{Z}_{t-1}+u_{i t}
\end{aligned}
$$

(using a heteroscedasticity-consistent estimator) and use the computed residuals to construct $\widehat{u}_{i t} / \sigma\left(y_{t+1 \mid t}\right) .{ }^{22}$ Finally, we compare the means in an analysis of variance (ANOVA) framework, after taking account of the differences in variance for different levels of the design variable (in this case, one for each member and a common effect corresponding to $\left.\beta^{*}\right)$. In this way, we can identify significant contrasts (difference in means) between $\mu$ and the $\mu_{i}$ 's, and between different $\mu_{i}$ 's, while allowing the variances of the heterogeneity term to differ across the members.

\subsection{A random coefficients model}

The random effects model in the previous subsection has the limitation that the restriction on the magnitudes of the random effect means ( $\mu$ and $\mu_{i}$ 's) depends on the design through $n$ and the $n_{i}$ 's. This limitation can be overcome

\footnotetext{
${ }^{20}$ Some recent work (Sibert, 2003, for example) suggest that such an assumption is justifiable from a theoretical point of view. This assumption also appears to be justified in the present context of members of the Bank of England MPC. The first vote against the motion for the 19 MPC members have been in meeting number $\left(1,1,2,4,4,5,8,8,8,9,9,9,9^{+}, 10,18,19,20,23,74^{+}\right)\left(^{+}\right.$denotes censored to the right). Further, none of the 19 members have proposed an interest rate lower than the consensus decision within the first 3 meetings; see also Hansen and McMahon (2008).

${ }^{21}$ This is not an unreasonable assumption; the squared multiple correlation coefficient of $\sigma\left(y_{t+1 \mid t}\right)$ on all the other exogenous regressors is 0.343 and that on the two expected output variables is only 0.054 , while the correlation coefficient between $\sigma\left(y_{t+1 \mid t}\right)$ and $y_{t+1 \mid t}$ is only -0.096 .

${ }^{22}$ Since $r_{i t}$ and $\triangle r_{i t}$ are not directly observable, we use $\widehat{u}_{i t}=r_{i t, o b s}-\widehat{r}_{i t}$ as a proxy, where $\widehat{r}_{i t}$ is obtained using the estimates from the above regression. This construction of pseudo residuals, $\widehat{u}_{i t}$, would be asymptotically valid if the widths of the censoring windows reduce to zero as $n \longrightarrow \infty$.
} 
by considering the following random coefficients model:

$$
\begin{aligned}
\triangle r_{i t}= & \alpha_{0}+\alpha_{1} \cdot \Delta r_{t-1}+\alpha_{2} r_{t-1}+\alpha_{3} \pi_{t}+\alpha_{4} \pi_{t+1 \mid t}+\alpha_{5} y_{t \mid t}+\alpha_{6} y_{t+1 \mid t} \\
& +\alpha_{7} \sigma\left(\pi_{t+1 \mid t}\right)+\underline{\lambda}^{\prime} \underline{Z}_{t-1}+\beta_{i t} \mathbf{I}_{i t} \sigma\left(y_{t+1 \mid t}\right)+\varepsilon_{i t}, \\
& \beta_{i t} \text { are random coefficients independent of each other and of } \varepsilon_{i t}, \\
& \beta_{i t} \backsim N\left(\mu_{i}, \sigma_{i}^{2}\right), \varepsilon_{i t} \backsim N\left(0, \sigma^{2}\right) .
\end{aligned}
$$

Under the interval regression framework considered earlier, we first estimate the slope-heterogeneity fixed effects model:

$$
\begin{aligned}
\triangle r_{i t}= & \alpha_{0}+\alpha_{1} \cdot \Delta r_{t-1}+\alpha_{2} r_{t-1}+\alpha_{3} \pi_{t}+\alpha_{4} \pi_{t+1 \mid t}+\alpha_{5} y_{t \mid t}+\alpha_{6} y_{t+1 \mid t} \\
& +\alpha_{7} \sigma\left(\pi_{t+1 \mid t}\right)+\underline{\lambda}^{\prime} \underline{Z}_{t-1}+\beta_{i} \mathbf{I}_{i t} \sigma\left(y_{t+1 \mid t}\right)+\varepsilon_{i t} .
\end{aligned}
$$

Now, if we can estimate the regression residuals, $\widehat{\varepsilon}_{i t}$, the significance of differences in means (contrasts) can be tested, using

$$
\widehat{\beta}_{i t}=\frac{\widehat{\varepsilon}_{i t}}{\sigma\left(y_{t+1 \mid t}\right)}+\widehat{\beta}_{i}
$$

as a pseudo-sample from the distribution of $\beta_{i t}$. In our application, the residuals cannot be directly obtained, since the response variable is censored. However, one can either use $\widehat{\varepsilon}_{i t}=r_{i t, o b s}-\widehat{r}_{i t}$ as pseudo-residuals (as earlier), or bootstrap from the distribution of the $\varepsilon_{i t}$, and then use this sample to evaluate the contrasts. This would constitute another way to identify significant contrasts between different $\mu_{i}$ 's, while allowing the variances of the heterogeneity term to differ across the members.

\section{Results}

We estimate the fixed effects models (16) and (17) and the random effects model (18); estimates of the random coefficients model (19) are similar to the random effects model and are not reported here.

\subsection{Majority decisions of the MPC}

Table 2 presents parameter estimates and goodness-of-fit measures for the model in which the dependent variable is the actual decision implemented by the MPC. Results using OLS and interval regression are reported; multinomial logit estimates are similar. 
TABLE 2: Inflation Targeting Model Estimates, Majority MPC Interest Rate Decisions (Jul.1997 to Mar.2005) ${ }^{23}$

\begin{tabular}{|l|c|c|c|}
\hline Variables & $\begin{array}{c}\text { Ordinary } \\
\text { Least Squares }\end{array}$ & $\begin{array}{c}\text { Interval } \\
\text { Regression }\end{array}$ & $\begin{array}{c}\text { IV Interval } \\
\text { Regression }\end{array}$ \\
\hline \hline$\triangle r_{t-1}$ & $-0.091(0.107)$ & $-0.125(0.116)$ & $-0.139(0.104)$ \\
$r_{t-1}$ & $-0.019(0.042)$ & $-0.012(0.046)$ & $-0.0002(0.042)$ \\
$\pi_{t}$ & $0.010(0.053)$ & $0.022(0.046)$ & $0.042(0.053)$ \\
$\pi_{t+1 \mid t}$ & $0.123(0.037)^{*}$ & $0.149(0.038)^{* *}$ & $0.144(0.040)^{*}$ \\
$y_{t}$ & $0.005(0.033)$ & $0.019(0.035)$ & $0.015(0.031)$ \\
$y_{t+1 \mid t}$ & $0.115(0.057)^{* *}$ & $0.151(0.061)^{*}$ & $0.136(0.055)^{* *}$ \\
$\triangle u_{t}$ & $-0.185(0.091)$ & $-0.192(0.104)^{+}$ & $-0.163(0.090)^{+}$ \\
$P_{h s g, t}$ & $0.737(0.569)$ & $0.950(0.652)$ & $0.387(0.551)$ \\
$P_{F T S E, t}$ & $0.141(0.177)$ & $0.376(0.186)^{* *}$ & $0.033(0.177)$ \\
$P_{\text {exch,t }}$ & $0.005(0.003)$ & $0.006(0.004)$ & $0.009(0.004)^{* *}$ \\
$\sigma\left(y_{t+1 \mid t}\right)$ & $-0.386(0.508)$ & $-0.397(0.602)$ & $-0.580(0.511)$ \\
$\sigma\left(\pi_{t+1 \mid t}\right)$ & $0.897(0.569)$ & $0.980(0.606)$ & $1.432(0.040)^{* *}$ \\
constant & $-0.588(0.426)$ & $-0.892(0.528)^{+}$ & $-0.761(0.404)^{+}$ \\
\hline Number of meetings & 94 & 94 & 94 \\
Goodness of fit & $F(12,81)=7.55$ & Wald $\chi^{2}(12)=73.67$ & Wald $\chi^{2}(12)=105.76$ \\
& Prob. $>F=0.0000$ & Prob. $>\chi^{2}=0.0000$ & Prob. $>\chi^{2}=0.0000$ \\
& $\mathbb{R}^{2}=0.5032$ & Log pseudo-likelihood & Log pseudo-likelihood \\
& $R M S E=0.1249$ & $=-44.8800$ & $=-37.8870$ \\
\hline
\end{tabular}

It is clear that expected inflation and expected output matter for the interest rate decision; currently observed inflation and output play no significant role. This confirms the assertion of Section 2 that the Bank of England follows an inflation forecast regime. It is also noticeable that movements in the stock market and housing market are significant. The coefficients on unemployment and exchange rate have the right sign but are not significant. The impact of output uncertainty is negative, but not significant. By contrast the coefficient on inflation uncertainty is positive. ${ }^{24}$ Interestingly, the coefficients on $\triangle r_{t-1}$ and $r_{t-1}$ are never significant. ${ }^{25}$

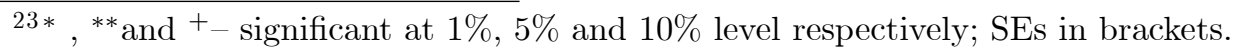

${ }^{24}$ The correlation between output and inflation uncertainty is very low, about 0.03 . The signs suggest that if there is an increase in uncertainty about output, conditional on all the other variables in the model, interest rates are likely to be lower than otherwise. While if there is an increase in uncertainty about inflation interest rates are likely to be raised.

${ }^{25}$ There is a large literature that tries to account for a common observation that interest rates are smoothed. The results here suggest that once we have conditioned on the set of
} 
However, there is a potential endogeneity issue. While it is reasonable to regard $\pi_{t}, y_{t}, y_{t+1 \mid t}, \triangle u_{t}$ and $P_{h s g, t}$ as weakly exogenous, the same is not true for $\pi_{t+1 \mid t}, P_{F T S E, t}$ and $P_{\text {exch, } t}$. Anticipation of interest rate decisions can lead to near contemporaneous movements in asset prices. Instrumental variable estimates of the interval regression model are also reported in Table $2 .{ }^{26}$ The results are broadly similar.

\subsection{Individual decisions under heterogeneity}

We now examine heterogeneity within the MPC using the published interest rate decisions of individual MPC members (over the period July 1997 to March 2005). In this case we are exploiting the extra information that is provided by the published voting records of each of the Committee members. In addition to a model where the votes of individual MPC members reveal their own (heterogeneous) types, we also estimate a model where the members belong to two types, depending on whether they are internal members (from the Bank of England) or external MPC members. ${ }^{27}$

In our model we include uncertainty in both output and inflation. However, we allow for heterogeneity only in output uncertainty. An LR test for the hypothesis of homogeneity in inflation uncertainty, after heterogeneity in output uncertainty is allowed for is not rejected (Likelihood ratio test (LRT): -2 . $\ln L=19.59,18$ d.f., $p$-value 0.356.). The same holds if we allow for heterogeneity in inflation uncertainty first. However, we have a model that allows us to interprete heterogeneity in the response to output uncertainty so we assume that there is a homogeneous response to inflation uncertainty.

explanatory variables, there appears to be no persistence in interest rates.

${ }^{26}$ We used as instruments 4 lags of the potentially endogenous variables as well as the remaining weakly exogenous variables. However, a Durban-Hausman test of endogeniety does not reject the null of weak endogeneity. The $p$-values for the test were $0.279,0.082$ and 0.360 for $\pi_{t+4 \mid t}, P_{F T S E, t}$ and $P_{\text {exch, },}$ respectively.

${ }^{27}$ See also Gerlach-Kristen (2003) for some similar analysis. Note that we classify John Vickers as an external member even though formally he was appointed as an internal member by the Bank of England. However, since he came straight from academia and returned there on his departure, classifying him as an external member seems more appropriate. 
TABLE 3: IV Model Estimates - Individual Members' Decisions ${ }^{28}$

\begin{tabular}{|c|c|c|c|}
\hline Variables & Indiv. members & Int. vs. Ext. & No heterogeneity \\
\hline$\overline{\Delta r_{t-1}}$ & "-0.114(0.043)* & $-0.112(0.044)^{* *}$ & $\overline{-0.116(0.046)^{* *}}$ \\
\hline$r_{t-1}$ & $-0.012(0.019)$ & $-0.018(0.019)$ & $-0.015(0.020)$ \\
\hline$\pi_{t+1 \mid t}$ & $0.124(0.015)^{*}$ & $0.121(0.014)^{*}$ & $0.122(0.015)^{*}$ \\
\hline$y_{t+1 \mid t}$ & $0.165(0.020)^{*}$ & $0.153(0.021)^{*}$ & $0.154(0.021)^{*}$ \\
\hline$\triangle u_{t}$ & $-0.198(0.033)^{*}$ & $-0.199(0.033)^{*}$ & $-0.193(0.034)^{*}$ \\
\hline$P_{h s g, t}$ & $1.148(0.195)^{*}$ & $1.336(0.191)^{*}$ & $1.314(0.195)^{*}$ \\
\hline$P_{F T S E, t}$ & $0.460(0.072)^{*}$ & $0.515(0.071)^{*}$ & $0.517(0.073)^{*}$ \\
\hline$P_{\text {exch }, t}$ & $0.010(0.002)^{*}$ & $0.010(0.002)^{*}$ & $0.009(0.002)^{*}$ \\
\hline$\sigma\left(\pi_{t+1 \mid t}\right)$ & $0.725(0.231)^{*}$ & $0.733(0.236)^{*}$ & $0.737(0.242)^{*}$ \\
\hline$\sigma\left(y_{t+1 \mid t}\right)$ & & & $-0.545(0.287)^{+}$ \\
\hline$-\times$ Allsopp & $-0.475(0.276)^{+}$ & & \\
\hline$-\times$ Barker & $-0.412(0.278)$ & & \\
\hline$-\times$ Bean & $-0.402(0.278)$ & & \\
\hline$-\times$ Bell & $-0.451(0.280)$ & & \\
\hline$-\times$ Budd & $-0.380(0.277)$ & & \\
\hline$-\times$ Buiter & $-0.410(0.275)$ & & \\
\hline$-\times$ Clementi & $-0.399(0.275)$ & & \\
\hline$-\times$ George & $-0.403(0.275)$ & & \\
\hline$-\times$ Goodhart & $-0.393(0.276)$ & & \\
\hline$-\times$ Julius & $-0.535(0.276)^{+}$ & & \\
\hline$-\times$ King & $-0.362(0.276)$ & & \\
\hline$-\times$ Lambert & $-0.411(0.282)$ & & \\
\hline$-\times$ Large & $-0.327(0.281)$ & & \\
\hline$-\times \operatorname{Lomax}$ & $-0.412(0.283)$ & & \\
\hline$-\times$ Nickell & $-0.425(0.277)$ & & \\
\hline$-\times$ Plenderleith & $-0.412(0.275)$ & & \\
\hline$-\times$ Tucker & $-0.342(0.280)$ & & \\
\hline$-\times$ Vickers & $-0.371(0.275)$ & & \\
\hline$-\times$ Wadhwani & $-0.513(0.275)^{+}$ & & \\
\hline$-\times$ INTERNAL & & $-0.495(0.280)^{+}$ & \\
\hline$-\times$ EXTERNAL & & $-0.560(0.280)^{* *}$ & \\
\hline constant & $-0.658(0.223)^{*}$ & $-0.572(0.187)^{*}$ & $-0.567(0.191)^{*}$ \\
\hline No. of member-meetings & 753 & 753 & 753 \\
\hline Fit: Wald $\chi^{2}\left(\right.$ Prob. $\left.>\chi^{2}\right)$ & $654.40(0.000)$ & $614.63(0.000)$ & $582.11(0.000)$ \\
\hline Log pseudo-likelihood & -533.50 & -553.38 & -569.64 \\
\hline
\end{tabular}

$28 *,{ }^{* *}$ and ${ }^{+}$- significant at $1 \%, 5 \%$ and $10 \%$ level respectively; SEs in brackets. 


\subsubsection{Fixed effects heterogeneity}

Table 3 reports interval regression estimates and goodness-of-fit measures for the fixed effects model (17) ${ }^{29}$ In contrast to the results in Table 2 we found it necessary to correct for endogeneity. We report, therefore, IV estimates using the same instruments as in Table 2 .

The broad conclusions from the model are similar to those for the aggregate, implemented decision of the MPC. However, we now find a more significant role for developments in asset markets. The higher significance of unemployment and asset market indicators may arise from either differing views among the MPC members or from larger sample size (since we are modelling individual decisions here). In particular, heterogeneity seems to be part of the explanation for the strong effect of unemployment; the coefficient in the committee decision regression (Table 2) lies outside the 95 per cent confidence interval of the estimate in Table 3. Although not individually significant, the heterogeneity coefficients are jointly significant at the 1 percent level. ${ }^{30}$

\subsubsection{Random effects heterogeneity}

The fixed effects estimates discussed above were not entirely satisfactory, since this setup does not allow us to explore individual specific heterogeneity after controlling for the "activism" apparent in some MPC members. Further, as our discussion of partisan responses points out, differences in private estimates of the output gap may be related to the degree of activism. Thus, while the lack of significance may be due to a lower sample size, we would like to control for the differences in variance in a random effects framework to have a closer look at the contrasts (differences in mean responses). ${ }^{31}$ Table 4 reports estimates of our random effects model (18) (estimation sample: July 1997 to March 2005).

\footnotetext{
${ }^{29}$ We have dropped the $\pi_{t}$ and $y_{t}$ from the following models since the terms are always insignificant.

${ }^{30}$ Joint significance of the 19 individual member heterogeneity terms - Likelihood ratio test (LRT): $-2 . \ln L=75.88,19$ d.f., $p$-value 0.000. Joint significance of the 'internal' and 'external' heterogeneity terms (LRT): $-2 . \ln L=36.11,2$ d.f., $p$-value 0.000 .

${ }^{31}$ This procedure ensures that the differences in individual (mean) effects are not masked by differences in variance - the so-called Behrens-Fisher problem.
} 
TABLE 4: Inflation Targeting Model Estimates, Individual Members' Interest Rate Decisions - Random Effects ${ }^{32,33,34}$

\begin{tabular}{|l|c|c|}
\hline Variables & $\widehat{\mu}_{i}$ & $\sqrt{\operatorname{Var}}\left(\beta^{*}+\beta_{i}\right)=\widehat{V}$ \\
\hline \hline Allsopp & $-0.0996^{*}$ & 0.1322 \\
Barker & -0.0239 & 0.1381 \\
Bean & -0.0099 & 0.1126 \\
Bell & -0.0465 & 0.1341 \\
Budd & 0.0408 & $\mathbf{0 . 1 4 7 0}$ \\
Buiter & 0.0118 & $\mathbf{0 . 2 1 4 9}$ \\
Clementi & 0.0130 & 0.1379 \\
George & 0.0003 & 0.1220 \\
Goodhart & 0.0334 & $\mathbf{0 . 1 6 3 1}$ \\
Julius & $-0.0882^{*}$ & 0.1369 \\
King & 0.0335 & 0.1426 \\
Lambert & -0.0003 & 0.1454 \\
Large & 0.0571 & 0.1438 \\
Lomax & 0.0003 & 0.1362 \\
Nickell & -0.0280 & $\mathbf{0 . 1 5 3 4}$ \\
Plenderleith & 0.0093 & 0.1421 \\
Tucker & 0.0302 & 0.1412 \\
Vickers & 0.0445 & $\mathbf{0 . 1 5 5 0}$ \\
Wadhwani & $-0.0961^{*}$ & $\mathbf{0 . 1 4 8 1}$ \\
\hline \hline
\end{tabular}

The estimates capture several of the interesting features of heterogeneity discussed earlier. There are several significant contrasts, both with respect to the typical average response of monetary policy $\mu$ and between memberspecific average responses $\left(\mu_{i}\right.$ 's), and the estimates reflect the expected direction of these contrasts. The degree of "activism" in any member is reflected in the estimated variance of $\beta^{*}+\beta_{i}$, denoted $\widehat{V}$. For example, Willem Buiter is the most activist of all MPC members, but he did not have a particular bias in favour of lower or higher interest rates on average. By contrast, DeAnne Julius had a significant bias in favour of lower interest rates along

\footnotetext{
${ }^{32}$ The estimates do not explicitly assume independence of $\beta^{*}$ and $\beta_{i}$.

${ }^{33}$ Significant contrasts from $\widehat{\mu}=0.0411$ are indicated in the Table. Other significant contrasts are: $\mu_{\text {Goodhart }}-\mu_{\text {Julius }}: 0.1216^{+}, \mu_{\text {Goodhart }}-\mu_{\text {Allsopp }}: 0.1301^{+}, \mu_{\text {Goodhart }}-$ $\mu_{\text {Wadhwani }}: 0.1295^{+}, \mu_{\text {King }}-\mu_{\text {Allsopp }}: 0.1301^{*}, \mu_{\text {King }}-\mu_{\text {Julius }}: 0.1217^{*}, \mu_{\text {King }}-\mu_{\text {Wadhwani }}:$ $0.1295^{*}, \mu_{\text {Large }}-\mu_{\text {Julius }}: 0.1453^{* *}, \mu_{\text {Large }}-\mu_{\text {Allsopp }}: 0.1537^{* *}, \mu_{\text {Large }}-\mu_{\text {Wadhwani }}: 0.1532^{* *}$, $\mu_{\text {Vickers }}-\mu_{\text {Allsopp }}: 0.1411^{+}$, and $\mu_{\text {Vickers }}-\mu_{\text {Wadhwani }}: 0.1405^{+}$.

$34 *,{ }^{* *}$ and ${ }^{{ }^{-}}$-significant at $1 \%, 5 \%$ and $10 \%$ level respectively; SEs in brackets.
} 


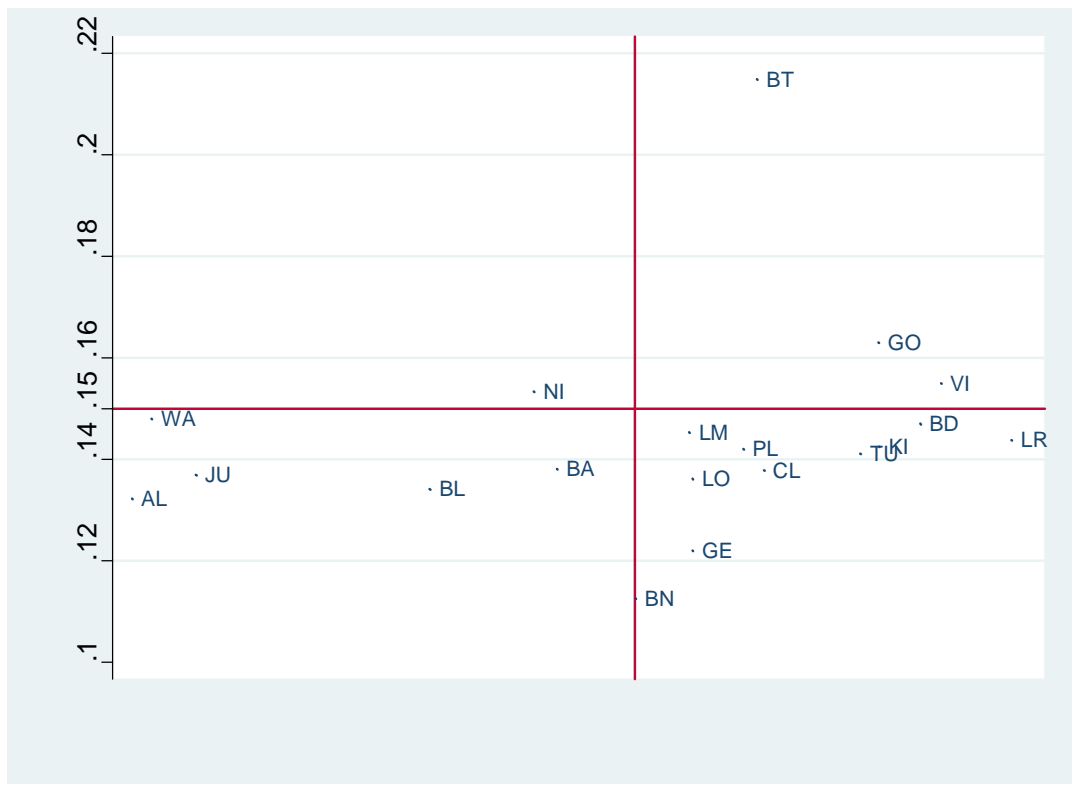

Figure 3: Spatial voting patterns of individual MPC members (Name codes: Table 5)

with Christopher Allsopp and Sushil Wadhwani, but they were not more activist than the average. Charlie Bean stands out as being both close on average to the actual MPC decision and about the least activist.

\subsubsection{Dove-Hawk versus Activist-Pacifist}

In the context of the model of rational partisan behaviour presented earlier, we now attempt to classify MPC members into types, based on their estimated positions along the dove-hawk dimension and their degree of activism. In Figure 3, we follow the spatial voting approach and plot the positions of each individual member on the above two dimensional preference space. Several important observations emerge from the plot.

First, the two dimensions, the traditional partisan dove-hawk scale and activism, are somewhat related. Extreme doves and hawks are relatively pacifist, while centrist members are either activist or pacifist. At the same time, the dimensions are linearly almost orthogonal, which provides empirical justification for classification along these dimensions. Second, and more im- 
portantly, the positions occupied by external and internal members are very well separated in this preference space. Specifically, as demonstrated in Table 5, all internal members are pacifist-hawks, while most external members are either activists or pacifist-doves. ${ }^{35}$

TABLE 5: Classification in the Preference Space

\begin{tabular}{|c|c|c|}
\hline Categories/Members & Status/Background & First meeting \\
\hline \hline ACTIVIST $(\widehat{V}>0.146)$ & & \\
- Buiter $(\mathrm{BT})$ & External-Academia & June 1997 \\
- Goodhart $(\mathrm{GO})$ & External-Academia & June 1997 \\
- Nickell $(\mathrm{NI})$ & External-Academia & June 2000 \\
- Vickers (VI) & External-Academia & June 1998 \\
- Budd $(\mathrm{BD})$ & External-Government & Dec 1997 \\
PACIFIST-HAwK $\left(\widehat{V}<0.146, \widehat{\mu}_{i}>-0.01\right)$ & & \\
- Lomax $(\mathrm{LO})$ & Internal & July 2003 \\
- Large $(\mathrm{LR})$ & Internal & Oct 2002 \\
- King $(\mathrm{KI})$ & Internal & June 1997 \\
- Plenderleith $(\mathrm{PL})$ & Internal & June 1997 \\
- Clementi $(\mathrm{CL})$ & Internal & Sept 1997 \\
- George $(\mathrm{GE})$ & Internal & June 1997 \\
- Bean $(\mathrm{BN})$ & Internal & Oct 2000 \\
- Tucker $(\mathrm{TU})$ & Internal & June 2002 \\
- Lambert $(\mathrm{LM})$ & June 2003 \\
PACIFIST-Dove $\left(\widehat{V}<0.146, \widehat{\mu}_{i}<-0.01\right)$ & External-Journalism & \\
- Bell $(\mathrm{BL})$ & & \\
- Julius $(\mathrm{JU})$ & External-Finance & July 2002 \\
- Wadhwani $(\mathrm{WA})$ & External-Industry & Sept 1997 \\
- Allsopp $(\mathrm{AL})$ & External-Finance & June 1999 \\
- Barker $(\mathrm{BA})$ & External-Academia & June 2000 \\
\hline \hline
\end{tabular}

These observations have very important implications for policy relating to institutional setting and political economy of monetary policy decision making. This is particularly relevant against the context of the recent observation (Hix et al., 2007) of a link between appointments to the MPC and political cycles. In particular, our observation that pacifist external members

\footnotetext{
${ }^{35}$ An alternative classification as Dove (and Pacifist), Hawk (and Pacifist), CentristActivist and Centrist-Pacifist shows an association with internal/ external status and background which falls along very similar lines.
} 
are doves rather than hawks emphasizes the usefulness of appointing MPC members in a way that can counteract 'conservative' monetary policy and replicate the social optimum; see also Waller $(1992,2007)$.

Further, our observation that external MPC members are more likely to be activist supports the view that individual members have incentives to gain a reputation for inflationary toughness; therefore, some members may choose to masquerade as conservative central bankers in the early part of their tenure in the MPC (Sibert, 2003). In this monetary policy setting, committee decision making leads to higher expected social welfare. Also, lower transparency in the form of delayed publication of votes reduces incentives for such strategic behaviour. Relatedly, Felgenhauer and Grüner (2008) show that transparency in the presence of external influence provides additional incentives for strategic voting by non-pivotal members in monetary policy committees, even when median voting rule is used. Thus, our observed structure of the preference space has important implications for design of committee structure, voting rules as well as appointment procedures.

Finally, Besley et al. (2008) estimate Taylor rules for different MPC members and find no significant differences between internal and external members, and neither between members from different backgrounds. Their inference is based on the observation that confidence bands for long-run coefficients in individual Taylor rules tend to overlap. At a first glance, their conclusions appears to be in contradiction with our results, as well as those reported by other authors (see, for example, Hix et al., 2007 and GerlachKristen, 2004). However, the substantial variation in the width of confidence bands reported in Besley et al. (2008) is closely related to the activism dimension highlighted in this paper. Notwithstanding important differences in the estimated models, these results are in concurrence with our finding that the activism dimension cannot be ignored in studies on heterogenity in monetary policymaking.

\section{Conclusions}

In this paper we have considered the conduct of UK monetary policy from 1997. Since then the Bank of England has had operational independence and decisions on interest rates made by the majority verdict of a Monetary Policy Committee. An enormous amount of information is provided about the data made available to the MPC and the decisions on interest rates 
decided upon by individual members. We find that an inflation forecast regime best describes what the MPC does but we also find an important role for developments in foreign exchange, equity and housing markets, once we exploit the extra information that is available in the individual voting records of MPC members. A role can also be found for unemployment. It is an open question whether our ability to detect a role for variables other than inflation and output is due to heterogeneity across the members of the MPC. In other words individual members may attach some importance to developments in asset markets and reflect these in an individual decision, which does not get carried through to the collective decision.

Our model of monetary policy decision making within a commitee setting highlight the way in which position of individual policy makers in the preference space translate into different reaction to uncertainty in the output gap. Further, we find evidence of heterogeneity in the way uncertainty about future levels of output and output gap affect the interest rate decisions of individual MPC members. This heterogeneity is reflected in differences in preferred interest rate changes across members of the MPC.

Further, our analysis of spatial voting behaviour highlight an important and hitherto unreported role for activism in partisan monetary policy reactions. This framework aligns itself remarkably with the background and status of MPC members and has important implications for institutional structure and political economy of monetary policy decision making. Further analysis of these issues are important topics for future study.

\section{References}

[1] Alesina, A. (1987). Macroeconomic policy in a two-party system as a repeated game. Quarterly Journal of Economics 102, 651-678.

[2] Alesina, A. (1988). Credibility and policy convergence in a two-party system with rational voters. American Economic Review 78, 496-805.

[3] Alesina, A. and Summers, L.H. (1993). Central bank independence and macroeconomic performance: some international evidence. Journal of Money, Credit, and Banking 25, 151-162.

[4] Amemiya, T. (1973). Regression analysis when the dependent variable is truncated normal. Econometrica 41, 997-1016. 
[5] Bank of England (2006). Minutes of the Monetary Policy Committee meeting held on 6 and 7 September 2006. (available from http://www.bankofengland.co.uk/publications/minutes/mpc/pdf/2006/index.htm).

[6] Belden, S. (1989). Policy preferences of FOMC members as revealed by dissenting votes. Journal of Money, Credit and Banking 21 (4), 432-441.

[7] Berlemann, M. and Markwardt, G. (2007). Unemployment and inflation consequences of unexpected election results. Journal of Money, Credit and Banking 39, 1919-1945.

[8] Bernanke, B.S. and Gertler, M. (2001). Should central banks respond to movements in asset prices?. American Economic Review 91(2), 253-257.

[9] Besley, T., Meads, N. and Surico, P. (2008). Insiders versus outsiders in monetary policymaking. American Economic Review: Papers 63 Proceedings 98 (2), 218-223.

[10] Bhattacharjee, A., and Holly, S. (2008), Taking personalities out of monetary policy decision making? interactions, heterogeneity and committee decisions in the Bank of England's MPC. Mimeo. Previous version available as: CDMA Working Paper 0612 (2006), Centre for Dynamic Macroeconomic Analysis, University of St. Andrews, UK..

[11] Bicchieri, C (1993). Rationality and Coordination. Cambridge: Cambridge University Press.

[12] Black, D. (1958). The theory of committees and elections. Cambridge: Cambridge University Press.

[13] Bomberger, W.A. (1996). Disagreement as a measure of uncertainty. Journal of Money, Credit and Banking 28 (4), 381-392.

[14] Britton, E., Fisher, P.G. and Whitley, J.D. (1998). The inflation report projections: understanding the fan chart. Bank of England Quarterly Bulletin 38, 30-37.

[15] Budd, A. (1998). The role and operations of the Bank of England Monetary Policy Committee. Economic Journal 108 (451), 1783-1794.

[16] Carlsen, F. and Pedersen, E.F. (1999). Rational partisan theory: evidence for seven OECD economies. Economics and Politics 11, 13-32. 
[17] Cecchetti, S.G., Genberg, H., Lipsky, J. and Wadhwani, S. (2000). Asset prices and central bank policy. Geneva Reports on the World Economy No. 2, International Center for Monetary and Banking Studies and Centre for Economic Policy Research, Geneva.

[18] Chadha, J. and Nolan, C. (2001). Inflation targeting, transparency and interest rate volatility: ditching "monetary mystique" in the UK. Journal of Macroeconomics 23 (3), 349-366.

[19] Chappell, H.W., Jr. and Keech, W.R. (1986). Party differences in macroeconomic policies and outcomes. American Economic Review 76, 71-74.

[20] Chappell, H.W., Jr. and McGregor, R.R. (2004). Did time inconsistency contribute to the great inflation? evidence from the FOMC transcripts. Economics and Politics 16, 233-251.

[21] Chappell, H.W., Jr., McGregor, R.R. and Vermilyea, T. (2005). Committee Decisions on Monetary Policy: Evidence from Historical Records of the Federal Open Market Committee. MIT Press.

[22] Cobham, D. (2002a). The exchange rate as a source of disturbances: the UK 1979-2000. National Institute Economic Review 181, 96-112.

[23] Cobham, D. (2002b). The Making of Monetary Policy in the UK, 19752000. John Wiley: Chichester.

[24] Cobham, D. (2003). Why does the Monetary Policy Committee smooth interest rates?. Oxford Economic Papers 55 (3), 467-493.

[25] Corrado, C. and Greene, M. (1988). Reducing uncertainty in short-term projections: linkages of monthly and quarterly models, Journal of Forecasting 7, 77-102.

[26] Downs, A. (1957). An Economic Theory of Democracy. New York: Harper.

[27] Felgenhauer, M. and Grüner, H.P. (2008). Committees and special interests. Journal of Public Economic Theory 10, 219-243.

[28] Geanakoplos, J. (1992). Common knowledge, Journal of Economic Perspectives $\mathbf{6}, 53-82$. 
[29] Gerlach-Kristen, P. (2003). Monetary policy committees and the benefits of deliberation, Mimeo, University of Basel.

[30] Gerlach-Kristen, P. (2004). Is the MPC's voting record informative about future UK monetary policy?. Scandinavian Journal of Economics 106 (2), 299-314.

[31] Gerling, K., Grüner, H.P., Kiel, A. and Schulte, E. (2005). Information acquisition and decision making in committees: a survey. European Journal of Political Economy 21, 563-597.

[32] Goodhart, C.A.E. (2001). Monetary transmission lags and the formulation of the policy decision on interest rates. Federal Reserve Bank of St Louis Review $\mathbf{8 3}$ (4), 165-181.

[33] Hansen, S. and McMahon, M. (2008). Delayed doves: MPC voting behaviour of externals. CEP Discussion Paper 862, Centre for Economic Performance, London School of Economics and Political Science, London, UK.

[34] Havrilesky, T.M., Gildea, J.A. (1992). Reliable and unreliable partisan appointees to the board of governors. Public Choice 73, 397-417.

[35] Hibbs, D. (1994). The partisan theory of macroeconomic cycles: more theory and evidence. Economics and Politics 6, 1-23.

[36] Hix, S., Hoyland, B. and Vivyan, N. (2007). From doves to hawks: a spatial analysis of voting in the Monetary Policy Committee of the Bank of England, 1997-2007. LSE PSPE Working Paper No. 8, London School of Economics.

[37] King, M. (2002). The Monetary Policy Committee five years on. Address to the Society of Business Economists, London, 22 May 2002 (available from http://www.bankofengland.co.uk/speeches/speaker.htm).

[38] Lagerlöf, J. (2001). Costly information acquisition and delegation to a "liberal" central banker. Economics and Politics 13, 221-236.

[39] McGregor, R.R. (1996). FOMC voting behaviour and electoral cycles: partisan ideology and partisan loyalty. Economics and Politics 8, 17-32. 
[40] Meade, E.E. and Stasavage, D. (2004). Publicity of debate and the incentive to dissent: evidence from the US Federal Reserve. Mimeo, London School of Economics, February.

[41] Morton, R.B. (1996). Partisan electoral cycles and monetary policy games. In Schofield, N. and Milford, A. (Eds.) Collective Decisionmaking: Social Choice and Political Economy, Boston: Kluwer, 363384.

[42] Neumann, M.J.M (2002). Transparency in monetary policy. Atlantic Economic Journal 30 (4), 353-365.

[43] Nordhaus, W.D. (1975). The political business cycle. Review of Economic Studies 42, 169-190.

[44] Orphanides, A. (1998). Monetary policy rules based on real-time data. Finance and Economics Discussion Series 1998-03, Board of Governors of the Federal Reserve System.

[45] Orphanides, A. (2003). Monetary policy evaluation with noisy information. Journal of Monetary Economics 50 (3), 605-631.

[46] Persson, T. and Tabellini, G. (1990). Macroeconomic Policy, Credibility and Politics. Chur: Harwood Academic Publishers.

[47] Sibert, A. (2003). Monetary policy committees: individual and collective reputations. Review of Economic Studies 70 (3), 649-665.

[48] Svensson, L. (1997a). Inflation forecast targeting: implementing and monitoring inflation targets. European Economic Review 41 (6), 11111146.

[49] Svensson, L. (1997b). Inflation targeting: some extensions. Working Paper IIES, Stockholm, February.

[50] Taylor, J.B. (1993). Discretion versus policy rules in practice. CarnegieRochester Conference Series on Public Policy 39, 195-214.

[51] Waller, C.J. (1992). The choice of a conservative central banker in a multisector economy. American Economic Review 82, 1006-1012. 
[52] Waller, C.J. (2007). Central bank conservatism, partisanship and policy by committee. Mimeo, University of Notre Dame.

[53] Woodford, M. (1999). Optimal monetary policy inertia. NBER Working Paper No $\mathbf{7 2 6 1 .}$ 